\title{
Patterned, But Not Tonic, Optogenetic Stimulation in Motor Thalamus Improves Reaching in Acute Drug-Induced Parkinsonian Rats
}

\author{
Sonja Seeger-Armbruster, ${ }^{1}$ Clémentine Bosch-Bouju, ${ }^{2}$ Shane T.C. Little, ${ }^{2}$ Roseanna A. Smither, ${ }^{1}$ Stephanie M. Hughes, ${ }^{3}$ \\ Brian I. Hyland, ${ }^{1}$ and Louise C. Parr-Brownlie ${ }^{2}$ \\ Departments of ${ }^{1}$ Physiology, ${ }^{2}$ Anatomy, and ${ }^{3}$ Biochemistry, Otago School of Medical Science, Brain Health Research Centre, University of Otago, Dunedin \\ 9054, New Zealand
}

\begin{abstract}
High-frequency deep brain stimulation (DBS) in motor thalamus (Mthal) ameliorates tremor but not akinesia in Parkinson's disease. The aim of this study was to investigate whether there are effective methods of Mthal stimulation to treat akinesia. Glutamatergic Mthal neurons, transduced with channelrhodopsin-2 by injection of lentiviral vector (Lenti.CaMKII.hChR2(H134R).mCherry), were selectively stimulated with blue light $(473 \mathrm{~nm})$ via a chronically implanted fiber-optic probe. Rats performed a reach-to-grasp task in either acute drug-induced parkinsonian akinesia $(0.03-0.07 \mathrm{mg} / \mathrm{kg}$ haloperidol, s.c.) or control (vehicle injection) conditions, and the number of reaches was recorded for $5 \mathrm{~min}$ before, during, and after stimulation. We compared the effect of DBS using complex physiological patterns previously recorded in the Mthal of a control rat during reaching or exploring behavior, with tonic DBS delivering the same number of stimuli per second (rate-control 6.2 or $1.8 \mathrm{~Hz}$, respectively) and with stimulation patterns commonly used in other brain regions to treat neurological conditions (tonic $130 \mathrm{~Hz}$, theta burst (TBS), and tonic $15 \mathrm{~Hz}$ rate-control for TBS). Control rats typically executed $>150$ reaches per $5 \mathrm{~min}$, which was unaffected by any of the stimulation patterns. Acute parkinsonian rats executed $<20$ reaches, displaying marked akinesia, which was significantly improved by stimulating with the physiological reaching pattern or TBS (both $p<0.05$ ), whereas the exploring and all tonic patterns failed to improve reaching. Data indicate that the Mthal may be an effective site to treat akinesia, but the pattern of stimulation is critical for improving reaching in parkinsonian rats.
\end{abstract}

Key words: motor thalamus; optogenetic stimulation; Parkinson's disease; patterns of stimulation; reaching task; theta burst stimulation

\section{Introduction}

Deep brain stimulation (DBS) of the subthalamic nucleus (STN) or globus pallidus internus (GPi) is used to treat bradykinesia, akinesia, and postural rigidity in Parkinson's disease (PD) patients (Lyons, 2011). Other brain sites, such as the pedunculopontine tegmental nucleus (PPN) or the motor thalamus (Mthal), are stimulated to improve gait or tremor, respectively (Limousin et al., 1999; Pereira et al., 2011). Mthal is an attractive target for DBS approaches because it is the final integration site of motor information from basal ganglia (BG) and cerebellar (CB) circuits that is passed to the cortex (Bosch-Bouju et al., 2013). However, standard DBS frequencies applied to the Mthal do not

Received Aug. 7, 2014; revised Nov. 9, 2014; accepted Nov. 30, 2014.

Author contributions:S.M.H., B.I.H., and L.C.P.-B. designed research;S.S.-A., C.B.-B., S.T.C.L., R.A.S., and L.C.P.-B. performed research; S.S.-A., C.B.-B., S.T.C.L., R.A.S., S.M.H., B.I.H., and L.C.P.-B. analyzed data; S.S.-A., C.B.-B., S.M.H., B.I.H., and L.C.P.-B. wrote the paper.

This work was supported by Health Research Council of New Zealand Grant to B.I.H., L.C.P.-B., and S.M.H. We thank Professor Karl Deisseroth for sharing the channelrhodopsin construct.

The authors declare no competing financial interests.

Correspondence should be addressed to Dr. Louise C. Parr-Brownlie, Department of Anatomy, University of Otago, P.0. Box 913, Dunedin 9054, New Zealand. E-mail: louise.parr-brownlie@otago.ac.nz.

C. Bosch-Bouju's present address: Institut National de la Recherche Agronomique, Nutrition and Integrative Neurobiology, Unité Mixte de Recherche 1286, University of Bordeaux, 33076 Bordeaux, France.

DOI:10.1523/JNEUROSCI.3277-14.2015

Copyright $\odot 2015$ the authors $\quad 0270-6474 / 15 / 351211-06 \$ 15.00 / 0$ improve akinesia or rigidity (Hariz et al., 2008), possibly because these stimulation parameters are not suitable.

The frequency of DBS that best improves movements in patients is dependent on the nucleus being stimulated, with highfrequency stimulation $(130-160 \mathrm{~Hz})$ in BG effective for akinesia (Moro et al., 2002), whereas gait is improved by low-frequency stimulation $(<50 \mathrm{~Hz})$ of PPN (Pereira et al., 2011). Conversely, low-frequency stimulation in STN and GPi worsen symptoms (Benabid et al., 1991; Limousin et al., 1995; Gradinaru et al., 2009). To date, DBS protocols are applied at a fixed frequency, which do not mimic normal patterns of activity. Instead, DBS may disrupt abnormal activity in the BG (Carlson et al., 2010) or enhance cortical excitability (Dejean et al., 2009), thereby allowing compensatory processes to restore function.

An alternative protocol to simple tonic stimuli is to apply natural patterns to replace pathological activity. This approach improves memory function in animals with lesions in circuits that normally provide the hippocampus with theta rhythm (McNaughton et al., 2006). Similarly, "theta burst" patterns of stimulation (TBS) applied to the motor cortex (MCx) using transcranial magnetic stimulation has been used to modulate function in patients with PD and following stroke, with mixed success (Huang et al., 2005; Udupa and Chen, 2013; Yamada et al., 2014), perhaps because of nonselective activation of cortical 


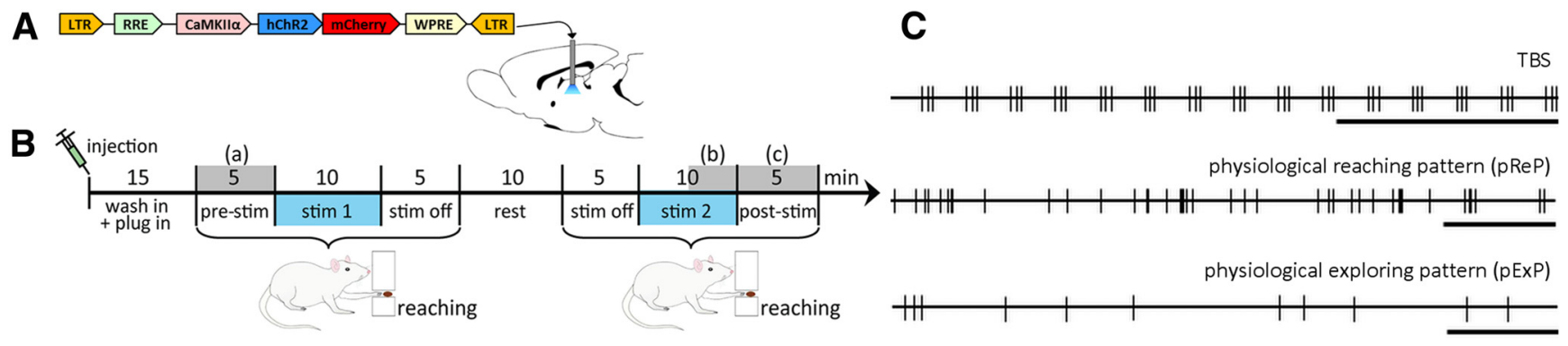

Figure 1. Experimental details. $\boldsymbol{A}$, Schematic of the lentiviral construct. $\boldsymbol{B}$, Experimental timeline. Experiments began when haloperidol $(0.03-0.07 \mathrm{mg} / \mathrm{kg}$, S.c.) or saline was injected. Reaching was recorded before (pre-stim), during (stim), and after (stim off or post-stim) light stimulation. Statistical comparisons were made of reaching performance during gray shaded periods (a-c). $C$ Example stimulation trains. Top, TBS. Middle, bottom, Segments from neuronal spike times recorded in a control rat during reaching (pReP) or open field exploration (pExP). Calibration: $1 \mathrm{~s}$.

networks. Another way to selectively activate subpopulations of cortical neurons is to enhance Mthal inputs to specific cortical layers through thalamocortical motor pathways.

Therefore, we investigated whether DBS in the ventroanterior (VA) Mthal using particular stimulation patterns and frequencies ameliorates parkinsonian akinesia in an acute drug-induced rat model. Further, we ensured specificity for Mthal projection neurons using optogenetic methods to target glutamatergic neurons (Gradinaru et al., 2009). We found that application of a natural pattern derived from the Mthal of a control rat performing reaching movements (Bosch-Bouju et al., 2014) and TBS in VA Mthal significantly improved reaching performance.

\section{Materials and Methods}

All experiments were approved by the University of Otago Animal Ethics Committee. Adult male Wistar rats $(n=4)$ were maintained in a reversed $12 \mathrm{~h}$ light/dark cycle with restricted food $(18 \mathrm{~g} / \mathrm{d})$ and free water access. All experiments were conducted during the rats' dark cycle.

Before surgery, rats were trained to perform reach-to-grasp movements for $7 \mathrm{~d}(15 \mathrm{~min} / \mathrm{d})$, and the dominant paw was determined as described previously (Parr-Brownlie and Hyland, 2005). Briefly, rats reached through an opening in the wall of a Perspex box to obtain a cereal pellet (Coco Pops; Kellogg's) placed $30 \mathrm{~mm}$ beyond the wall on a platform. Reaches were detected by interruption of a light beam positioned $22 \mathrm{~mm}$ from the wall of the box, which was recorded using Spike2 (Cambridge Electronic Design; RRID:nlx 156886). Reaching in rats and humans is homologous, and similarly affected by parkinsonism (Whishaw et al., 1992; Parr-Brownlie and Hyland, 2005; Sacrey et al., 2009).

In preparation for light stimulation, rats $(358 \pm 21 \mathrm{~g})$ were deeply anesthetized with ketamine/medetomidine/atropine $(75 / 0.5 / 0.06 \mathrm{mg} / \mathrm{kg}$, s.c.; Phoenix Pharm/Pfizer Animal Health/Phoenix Pharm) and placed in a stereotaxic frame. A hole $(\sim 1.5 \mathrm{~mm}$ in diameter $)$ was drilled above VA Mthal contralateral to the dominant paw centered at anteroposterior $-2.25 \mathrm{~mm}$ and mediolateral $1.6 \mathrm{~mm}$ (relative to bregma) (Paxinos and Watson, 2007). The construct, pLenti.CaMKII.hChR2(H134R). $m$ Cherry. WPRE (Fig. 1A; Optogenetics Resource Centre, Stanford University, Stanford, CA), was packaged into a third-generation lentiviral vector pseudotyped with vesicular stomatitis virus glycoprotein by the Otago Viral Vector Facility (Linterman et al., 2011). Three injections of $0.5 \mu \mathrm{l}(0.1 \mu \mathrm{l} / \mathrm{min})$ of the viral vector were made into VA Mthal using a microsyringe (World Precision Instruments), centered at the target coordinates $(-6.0 \mathrm{~mm}$ below dura), and additional injections were located $0.2 \mathrm{~mm}$ on either side. The cannula remained in place for 5-10 min after the infusion before being slowly withdrawn. A fiber-optic probe (MFC_240/245-0.37_14mm_ZF1.25(F)-FLT; Doric Lenses) was centered where the virus had been injected, lowered $-5.8 \mathrm{~mm}$ below the dura, fixed using dental acrylic (Vertex-Dental, AA Zeist), and four stainless-steel screws implanted into the skull. Experiments began 3-4 weeks later to allow for channelrhodopsin-2 (ChR2) expression.

To induce reversible parkinsonian akinesia, rats were injected with the dopamine receptor antagonist haloperidol $(0.03-0.07 \mathrm{mg} / \mathrm{kg}$; s.c., Sigma) (Parr-Brownlie and Hyland, 2005) and placed in the reaching box
13-15 min later. An optical fiber was attached to the implanted fiberoptic probe and connected to the laser (Crystal Laser LC) via a fiber-optic rotary joint (Doric Lenses). Each experiment consisted of two $20 \mathrm{~min}$ blocks of reaching, separated by a $10 \mathrm{~min}$ rest period (Fig. $1 B)$. Blue (473 $\mathrm{nm}$ ) or yellow (561 nm) light (2 ms pulse duration) was applied for both blocks, but the color, pattern, and drug [haloperidol or vehicle $(0.9 \%$ saline)] were applied following a pseudorandom design. "Standard" patterns were tonic $130 \mathrm{~Hz}$, TBS [5 bursts/s (200 ms interburst interval) with 3 stimuli/burst (20 ms intraburst interval) (Huang et al., 2005) (Figure 1C)] and tonic $15 \mathrm{~Hz}$ (TBS rate-control, same number of pulses). "Physiological" patterns used the timing of spikes from previously recorded single VA neurons obtained from Bosch-Bouju et al. (2014); a typical physiological reaching pattern $(\mathrm{pReP})$ from a control rat performing the reaching task and a physiological exploring pattern ( $\mathrm{pExP}$ ) from another rat in an open field (not reaching; see example segments Fig. 1C). The spike train segments were 10 and $5 \mathrm{~min}$ in duration for $\mathrm{pReP}$ and $\mathrm{pExP}$, respectively, and the pExP segment was repeated to achieve 10 min of stimulation. These patterns were paired with appropriate tonic ratecontrols (mean rates of 6.2 and $1.8 \mathrm{~Hz}$, respectively). After haloperidol experiments, there was at least one nonexperimental day to allow clearance of the drug, followed by a vehicle experiment. There were at least $72 \mathrm{~h}$ between haloperidol experiments to minimize possible sensitization effects.

The number of reaches per 5 min period was recorded. Blue (13-20 $\left.\mathrm{mW} / \mathrm{mm}^{2}\right)$ and yellow $\left(20-26 \mathrm{~mW} / \mathrm{mm}^{2}\right)$ light power exceeded the $5-12 \mathrm{~mW} / \mathrm{mm}^{2}$ required to activate ChR2 (Zhang et al., 2006). To exclude experiments where the haloperidol injection failed to produce adequate akinesia, we analyzed the number of reaches in the prestimulation (pre-stim) reach periods and rejected outliers using the robust regression and outlier removal method with Q $=1 \%$ (PRISM 6; GraphPad Software; RRID:nlx 156835). This led to rejection of 13 of 105 haloperidol experiments. The average number of individual experiments per rat in the study was 15 and 24 (ranges: 12-19 and 14-28) for vehicle and haloperidol experiments, respectively. Data are presented as mean \pm SEM. Statistical comparisons were performed on preselected behavioral epochs of interest using PRISM: prestimulation (a), the last 5 min of stimulation (end of second stimulation, stim; b), and the 5 min of poststimulation (post-stim, c), as indicated in Figure $1 B$ (gray), using twoway repeated-measures ANOVA and Tukey's multiple-comparisons post hoc tests. Effect sizes were calculated according to Lakens (2013) and are presented as partial $\eta$ square $\left(\eta_{p}^{2}\right)$ to indicate the variance attributed to main effects.

At the completion of experiments, rats $(461 \mathrm{~g} \pm 27 \mathrm{~g})$ were transcardially perfused with $4 \%$ paraformaldehyde solution and $40 \mu \mathrm{m}$ coronal brain sections cut on a microtome (Leica). Sections containing the fiberoptic probe were stained with neutral red (not shown) or immunostained to confirm localization in VA Mthal and check for transduction of VA neurons (Fig. $2 A-D$ ). Sections were triple stained: (1) to enhance the fluorescent signal for mCherry; (2) to show the location of glutamatergic neurons via CaMKII $\alpha$ or GABAergic neurons via glutamate decarboxylase (GAD67) (Gradinaru et al., 2009); then slices were mounted on slides; and (3) slices were stained with DAPI (Vectashield hardset, In Vitro Technologies) to show the location of nuclei (Fig. $2 C, D$ ). Primary 

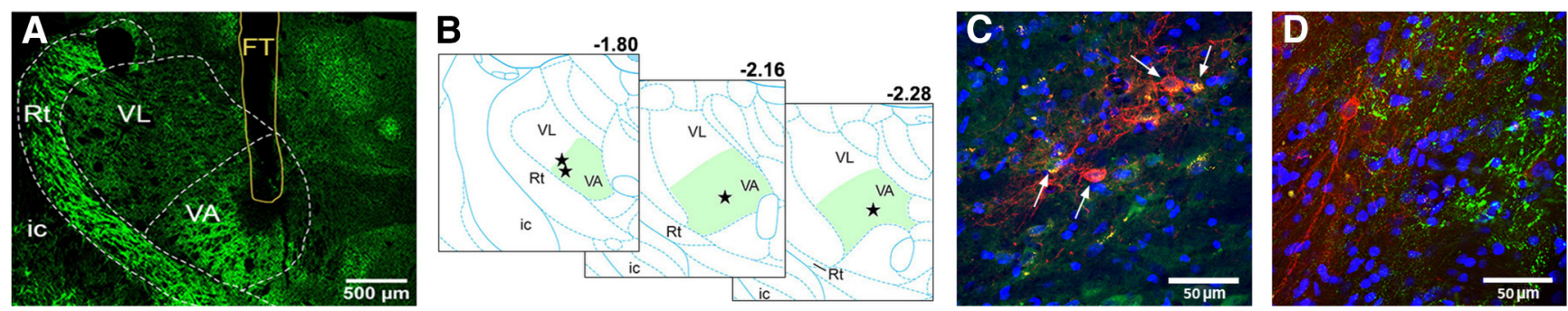

Figure 2. Fiber-optic probe locations and neuronal transduction. $A$, Low-magnification image of a coronal section ( $-2.04 \mathrm{~mm}$ from bregma) containing Mthal nuclei stained with GAD67 showing that the fiber-optic probe was in VA. Scale bar, $500 \mu \mathrm{m}$. B, Probe tip positions in VA Mthal on schematic coronal sections located -1.8 to $-2.28 \mathrm{~mm}$ relative to bregma (modified from Paxinos and Watson, 2007). C, $\boldsymbol{D}$, Confocal images of triple stained sections adjacent to $A$, indicating that neurons transduced with $m($ Cherry (red) colocalized with CaMKIll $\alpha(\boldsymbol{C}$, green, white arrows) or not colocalized with GAD67-stained GABAergic terminals (D, green), and DAPI-stained nuclei (blue). Scale bars, $50 \mu \mathrm{m}$. FT, Fiber track; ic, internal capsule; Rt, reticular thalamic nucleus; VA, ventroanterior Mthal; VL, ventrolateral Mthal.
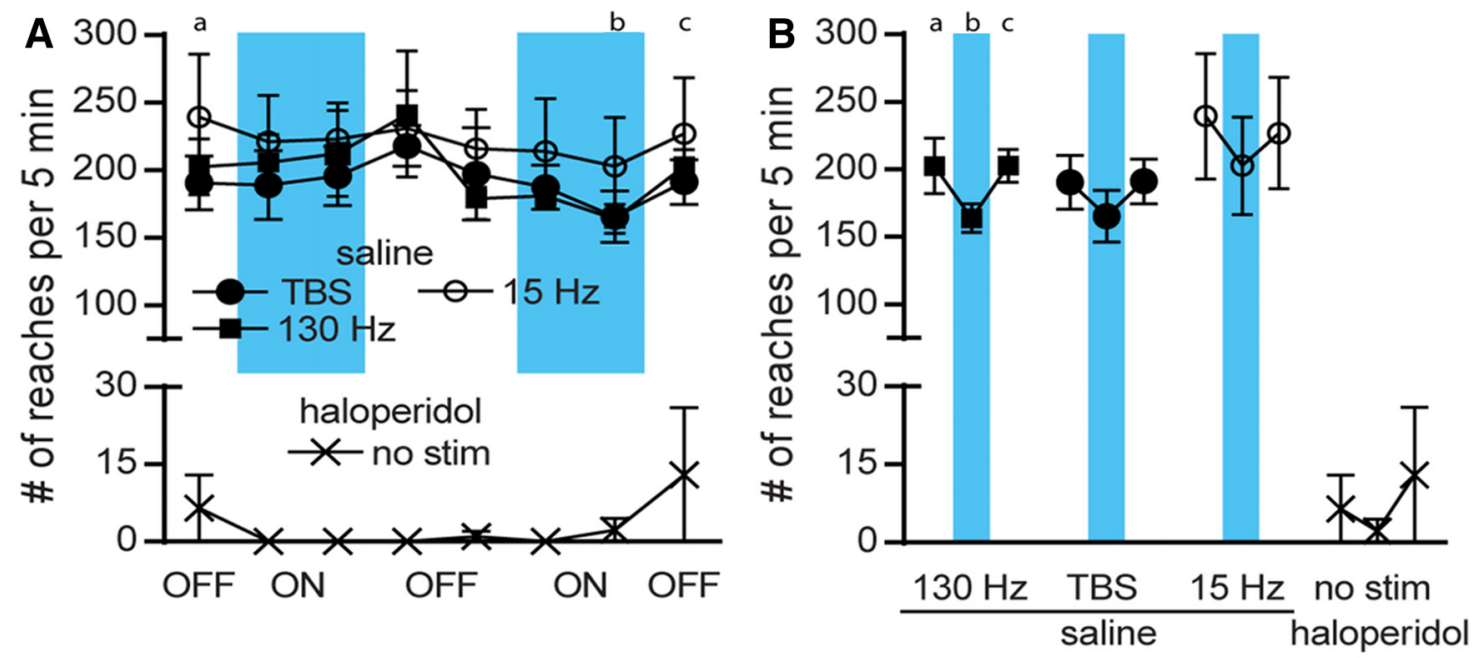

Figure 3. Reaches in control experiments. Blue bars represent times of blue light stimulation. $\boldsymbol{A}$, Standard stimulation patterns (tonic $130 \mathrm{~Hz}$, TBS, and tonic $15 \mathrm{~Hz}$ ) after saline injection (upper $y$-axis). Additional control experiment established the number of reaches following haloperidol injection without light stimulation (no stim, lower $y$-axis). Data show the number of reaches (mean \pm SEM) for each 5 min block before, during, or after stimulation. B, Comparison of critical time points shown in Figure 1: prestimulation (a), end of second stimulation (b), and poststimulation (c). Graphs show data on two scales: $0-30$ and $0-300$ reaches following haloperidol and vehicle injection, respectively. There are no significant differences between stimulation patterns.

antibodies (RFP antibody 5F8 rat for mCherry, Chromotek, 1:500, RRID:AB_2336064; mouse monoclonal anti-GAD67, Abacus, 1:1000, catalog \#MAB5406, RRID:AB_2278725; mouse monoclonal antiCaMKII $\alpha$, Abacus, 1:300, catalog \#05-532, RRID:AB_309787) were incubated overnight at $4^{\circ} \mathrm{C}$. Slices were incubated for $4 \mathrm{~h}$ at room temperature with secondary antibodies (goat anti-rat AlexaFluor-594, Invitrogen, 1:1500, catalog \#A-11007, RRID:AB_10561522; for GAD67 and CaMKII $\alpha$ : goat anti-mouse AlexaFluor-488, Invitrogen, 1:1500, catalog \#A11029, RRID:AB_138404). Images were taken with a confocal microscope (10× and $40 \times$ objectives; Nikon A1R).

\section{Results}

All animals had fiber-optic probe tips located in VA Mthal (Fig. $2 A, B)$. Triple labeling immunohistochemistry confirmed that transduced VA neurons expressing the mCherry reporter found close to the fiber-optic tip locations were positive for CaMKII $\alpha$, an excitatory glutamatergic marker (Fig. 2C), and did not coexpress the inhibitory GABAergic marker GAD67 (Fig. 2D).

The optimal activation wavelength for ChR2 is $\sim 470 \mathrm{~nm}$ (Zhang et al., 2006). To control for effects of applying light energy, we used yellow light, which did not significantly affect reaching performance in control or acute haloperidol-induced akinetic experiments for any of the stimulation patterns (data not shown). Additional controls are shown in Figure 3. First, the time course of unstimulated acute akinesia is illustrated in Figure $3 \mathrm{~A}$ (bottom $y$-axis). Here, rats were given haloperidol, but no light stimuli were administered, confirming that haloperidol-induced akinesia lasted throughout the recording session, with rats performing on average $<20$ reaches per 5 min period. Second, we tested the effect of blue light stimulation on reaching behavior in animals treated with vehicle. Reaching performance was stable over recording sessions, with rats executing $>150$ reaches per 5 min period, regardless of stimulation pattern $\left(F_{(2,9)}=1.045, p=\right.$ $\left.0.3906, \eta_{p}^{2}=0.19\right)$, indicating that animals maintained motivation to reach and did not become satiated (Fig. 3A). The lack of any significant difference between reaching in prestimulation, during stimulation, and poststimulation periods $\left(F_{(2,18)}=2.115\right.$, $p=0.1496, \eta_{p}^{2}=0.19$; Fig. $\left.3 B\right)$ confirmed that blue light stimulation did not disrupt normal reaching behavior.

The main results are shown in Figure 4, which illustrate the effect of blue light stimulation on reaching behavior in haloperidol-induced parkinsonian rats. Figure $4 A, B$ shows the mean reaches executed for the different stimulation protocols. For clarity, time course plots are split into data from standard (Fig. 4A) and physiological (Fig. 4B) stimulation protocols, but data were compared in one analysis. Although reaching performance was not altered during the first stimulation block, reaching improved steadily during TBS and pReP stimulation 

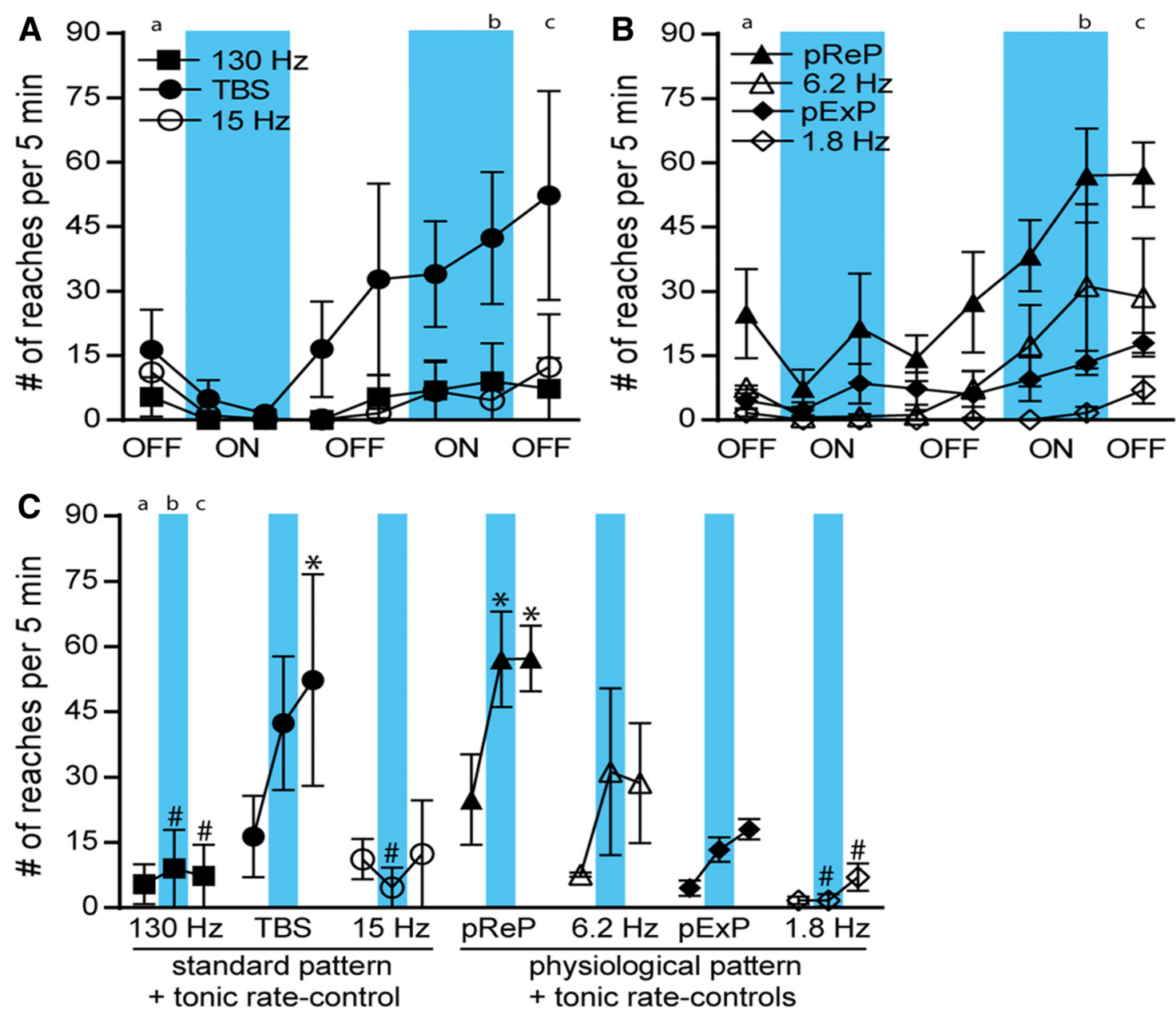

Figure 4. Reaches in haloperidol experiments. Blue bars represent when blue light stimulation was applied. $A$, Experiments with the same standard stimulation patterns (tonic $130 \mathrm{~Hz}$, TBS, and tonic $15 \mathrm{~Hz}$ ) as control experiments. $\boldsymbol{B}$, Experiments with physiological patterns (pReP and pExP) and tonic rate-control stimulation ( $6.2 \mathrm{and} 1.8 \mathrm{~Hz}$, respectively). $\boldsymbol{A}, \boldsymbol{B}$, Data show the number of reaches for each 5 min period. C, Comparison of critical time points: prestimulation (a), end of second stimulation (b), and poststimulation (c), for all stimulation patterns in haloperidol-treated rats. $y$-axes are on the same scale as the lower $y$-axis in Figure $3 .{ }^{*} p<0.05$ versus prestimulation (Tukey's test). ${ }^{\#} p<0.05$ versus pReP (Tukey's test).

experiments, with TBS data appearing to have greater variability. Clear differences were seen in reaching performance during and after stimulation for some stimulation protocols.

To quantitatively assess the effect of stimulation we applied planned contrasts at three specific time points: prestimulation, end of second stimulation, and poststimulation (Fig. 4C). A twoway repeated-measures ANOVA revealed that stimulation pattern had a strong significant effect on reaching performance $\left(F_{(6,19)}=4.470, p=0.0055, \eta_{p}^{2}=0.59\right)$, with time also significant and moderately effective $\left(F_{(2,38)}=5.639, p=0.0072, \eta_{p}^{2}=0.23\right)$, and no significant interactions. Post hoc tests for the effect of pattern confirmed that significantly more reaches occurred during pReP stimulation than tonic stimulation at 130,15 , or $1.8 \mathrm{~Hz}$ ( $p<0.05$, all comparisons). Reaching from the $6.2 \mathrm{~Hz}$ ratecontrol and TBS patterns did not differ significantly compared with pReP or any other stimulation pattern. Post hoc tests for the effect of time showed that none of the tonic stimulation patterns or the pExP improved reaching at either time point. In contrast, during the second stimulation period, reaching improved significantly with $\mathrm{pReP}$ compared with the prestimulation level $(p<$ $0.05)$, but not for TBS. Furthermore, this effect persisted for $\mathrm{pReP}$ and became significant for TBS during the poststimulation period ( $p<0.05$ for both comparisons), indicating a residual effect not dependent on continued stimulation. To investigate whether there was any simple correlation between the pReP stimulation protocol and reaching performance, we investigated the relationship between instantaneous rate and the timing of bursts of stimuli with each single reach event. None of these analyses revealed any significant correlation (data not shown).

\section{Discussion}

Mthal stimulation can rescue movement in acute haloperidolinduced parkinsonian rats, and the pattern of stimulation critically determined effectiveness. Several factors likely contributed to the significant improvement in akinesia following Mthal stimulation compared with previous human studies reporting that DBS is ineffective (Benabid et al., 1991; Hariz et al., 2008). The site of stimulation within Mthal may be important. Although this is difficult to compare across species because nomenclatures differ (Okun and Vitek, 2004), DBS for tremor treatment in humans is usually applied in the ventral intermediate Mthal, part of the CB-recipient zone (Kultas-Ilinsky et al., 2011), whereas the stimulation here was applied in VA, part of the BG-recipient zone. Generally, the closer the stimulation pattern mimicked Mthal neural activity associated with reaching in control rats, the better the treatment outcome.

Reaching performance was significantly improved by stimuli that mimicked real neuronal activity or the TBS pattern that in- 
cluded some interstimulus interval (ISI) variability. Interestingly, the TBS ISI distribution had a mean of $65 \mathrm{~ms}$ and peaks at 20 and $160 \mathrm{~ms}$, and the pReP had a mean of $129 \mathrm{~ms}$ (range 2-998 ms), midway between these TBS peaks. In contrast, $\mathrm{pExP}$ was ineffective and the mean ISI $(321 \mathrm{~ms})$ was outside the two TBS peaks. We used 2 ms stimulation pulses and the ChR2(H134R) variant to improve spiking fidelity. ChR2(H134R) can follow stimulation up to $80 \mathrm{~Hz}$ (Zhao et al., 2011); thus, TBS with $50 \mathrm{~Hz}$ intraburst frequency can reliably activate neurons (Lin et al., 2009; Zhao et al., 2011). Although channel kinetics would mean fidelity was $<100 \%$ at $130 \mathrm{~Hz}$ stimulation, significant behavioral effects have been reported (Gradinaru et al., 2009). Data indicate that physiological and TBS patterns should be trialed in PD patients to investigate whether there is greater recovery of movements than with high-frequency tonic patterns. Consistent with this, Brocker et al. (2013) reported that other nonregular DBS patterns applied to $B G$ nuclei were more efficacious at restoring movements in PD patients than tonic $185 \mathrm{~Hz}$ stimulation. Development of implantable pulse generators that produce burst patterns would enable these results to be rapidly translated to the clinic and further refinement of TBS protocols to have a peak closer to that of the pReP may improve its efficacy.

Applying physiological patterns of stimulation to restore brain function in vivo is in its infancy. McNaughton et al. (2006) have rescued learning and memory deficits by applying theta frequency stimulation, recorded from the supramammillary area, directly to septohippocampal inputs. Another approach to improve DBS outcome is using adaptive stimulation technology, which significantly improved motor symptoms in parkinsonian primates or patients when feedback from MCx or STN refined the BG stimulation pattern (Rosin et al., 2011; Little et al., 2013).

We used optogenetic techniques to specifically activate glutamatergic neurons in VA Mthal, which innervate premotor cortex (Bosch-Bouju et al., 2013). The lentiviral vesicular stomatitis virus glycoprotein packaging system ensured transduction of only somata of neurons at the injection site (Mazarakis et al., 2001) and thereby prevented stimulation of afferents to Mthal. However, if electrical DBS was applied to VA, it is possible that movement outcomes may differ because fibers of passage, afferent inputs, and somata would be activated (Yizhar et al., 2011). Interestingly, reaching performance in control rats was not affected by stimulation. Low-frequency stimulation may insufficiently disturb ongoing activity, whereas lack of effect of high frequencies may reflect an unreliable Mthal-MCx synapse (Lewis and O'Donnell, 2000).

Mthal stimulation may produce lasting change in the cortex that rescues reaching following acute reduction in dopaminergic function, rather than moment-to-moment modulation of cortical activity. This is supported by the fact that the therapeutic effect of stimulation in acute akinetic rats was delayed and cumulative and persisted beyond the stimulation period. Furthermore, the sequence of stimuli in the $\mathrm{pReP}$ did not correlate with the precise timing of reaching. Instead, appropriate Mthal activity may maintain flexibility and plasticity of cortical pathways to enable correctly patterned output for movements. Thus, variable stimulation, rather than the specific timing, may be critical for improving movements (Brocker et al., 2013). Indeed, natural patterns of stimulation, such as the $\mathrm{pReP}$ in our study, can modulate short-term plasticity in more complex ways (including facilitation and depression) than simple high-frequency patterns (Dobrunz and Stevens, 1999). This is relevant because it implies that specific sequences for specific movements are not required so long as appropriate ISI distributions optimize plasticity. Clin- ically, this is important as it suggests that intermittent, rather than continuous, stimulation may be sufficient, thus reducing energy delivery to the brain and improving stimulator battery life. Nevertheless, stimulating Mthal inputs to cortex may improve movements by increasing excitability in motor areas.

In conclusion, pReP and TBS both improved reaching in haloperidol-induced parkinsonian rats, whereas rate-control stimuli were ineffective. Stimulation patterns that closely capture these ISI statistics (rate and variability) may be most efficacious at restoring cortical excitability in parkinsonism and therefore effectively improve function. This is of practical and clinical significance because TBS is not a specific correlate of reaching or any other discrete movement; thus, it is not important that specific patterns for every desired movement need to be applied to achieve beneficial outcome.

\section{References}

Benabid AL, Pollak P, Gervason C, Hoffmann D, Gao DM, Hommel M, Perret JE, de Rougemont J (1991) Long-term suppression of tremor by chronic stimulation of the ventral intermediate thalamic nucleus. Lancet 337:403-406. CrossRef Medline

Bosch-Bouju C, Hyland BI, Parr-Brownlie LC (2013) Motor thalamus integration of cortical, cerebellar and basal ganglia information: implications for normal and parkinsonian conditions. Front Comput Neurosci 7:163. CrossRef Medline

Bosch-Bouju C, Smither RA, Hyland BI, Parr-Brownlie LC (2014) Reduced reach-related modulation of motor thalamus neural activity in a rat model of Parkinson's disease. J Neurosci 34:15836-15850. CrossRef Medline

Brocker DT, Swan BD, Turner DA, Gross RE, Tatter SB, Koop MM, BronteStewart H, Grill WM (2013) Improved efficacy of temporally nonregular deep brain stimulation in Parkinson's disease. Exp Neurol 239: 60-67. CrossRef Medline

Carlson JD, Cleary DR, Cetas JS, Heinricher MM, Burchiel KJ (2010) Deep brain stimulation does not silence neurons in subthalamic nucleus in Parkinson's patients. J Neurophysiol 103:962-967. CrossRef Medline

Dejean C, Hyland B, Arbuthnott G (2009) Cortical effects of subthalamic stimulation correlate with behavioral recovery from dopamine antagonist induced akinesia. Cereb Cortex 19:1055-1063. CrossRef Medline

Dobrunz LE, Stevens CF (1999) Response of hippocampal synapses to natural stimulation patterns. Neuron 22:157-166. CrossRef Medline

Gradinaru V, Mogri M, Thompson KR, Henderson JM, Deisseroth K (2009) Optical deconstruction of parkinsonian neural circuitry. Science 324: 354-359. CrossRef Medline

Hariz MI, Krack P, Alesch F, Augustinsson LE, Bosch A, Ekberg R, Johansson F, Johnels B, Meyerson BA, N'Guyen JP, Pinter M, Pollak P, von Raison F, Rehncrona S, Speelman JD, Sydow O, Benabid AL (2008) Multicentre European study of thalamic stimulation for parkinsonian tremor: a 6 year follow-up. J Neurol Neurosurg Psychiatry 79:694-699. CrossRef Medline

Huang YZ, Edwards MJ, Rounis E, Bhatia KP, Rothwell JC (2005) Theta burst stimulation of the human motor cortex. Neuron 45:201-206. CrossRef Medline

Kultas-Ilinsky K, Ilinsky IA, Verney C (2011) Glutamic acid decarboxylase isoform 65 immunoreactivity in the motor thalamus of humans and monkeys: $\gamma$-aminobutyric acidergic connections and nuclear delineations. J Comp Neurol 519:2811-2837. CrossRef Medline

Lakens D (2013) Calculating and reporting effect sizes to facilitate cumulative science: a practical primer for t-tests and ANOVAs. Front Psychol 4:863. CrossRef Medline

Lewis BL, O’Donnell P (2000) Ventral tegmental area afferents to the prefrontal cortex maintain membrane potential ' $U p$ ' states in pyramidal neurons via D1 dopamine receptors. Cereb Cortex 10:1168-1175. CrossRef Medline

Limousin P, Pollak P, Benazzouz A, Hoffmann D, Le Bas JF, Broussolle E, Perret JE, Benabid AL (1995) Effect on parkinsonian signs and symptoms of bilateral subthalamic nucleus stimulation. Lancet 345:91-95. CrossRef Medline

Limousin P, Speelman JD, Gielen F, Janssens M (1999) Multicentre European study of thalamic stimulation in parkinsonian and essential tremor. J Neurol Neurosurg Psychiatry 66:289-296. CrossRef Medline 
Lin JY, Lin MZ, Steinbach P, Tsien RY (2009) Characterization of engineered channelrhodopsin variants with improved properties and kinetics. Biophys J 96:1803-1814. CrossRef Medline

Linterman KS, Palmer DN, Kay GW, Barry LA, Mitchell NL, McFarlane RG, Black MA, Sands MS, Hughes SM (2011) Lentiviral-mediated gene transfer to the sheep brain: implications for gene therapy in Batten disease. Hum Gene Ther 22:1011-1020. CrossRef Medline

Little S, Pogosyan A, Neal S, Zavala B, Zrinzo L, Hariz M, Foltynie T, Limousin P, Ashkan K, FitzGerald J, Green AL, Aziz TZ, Brown P (2013) Adaptive deep brain stimulation in advanced Parkinson disease. Ann Neurol 74:449-457. CrossRef Medline

Lyons MK (2011) Deep brain stimulation: current and future clinical applications. Mayo Clin Proc 86:662-672. CrossRef Medline

Mazarakis ND, Azzouz M, Rohll JB, Ellard FM, Wilkes FJ, Olsen AL, Carter EE, Barber RD, Baban DF, Kingsman SM, Kingsman AJ, O'Malley K, Mitrophanous KA (2001) Rabies virus glycoprotein pseudotyping of lentiviral vectors enables retrograde axonal transport and access to the nervous system after peripheral delivery. Hum Mol Genet 10:2109-2121. CrossRef Medline

McNaughton N, Ruan M, Woodnorth MA (2006) Restoring theta-like rhythmicity in rats restores initial learning in the Morris water maze. Hippocampus 16:1102-1110. CrossRef Medline

Moro E, Esselink RJ, Xie J, Hommel M, Benabid AL, Pollak P (2002) The impact on Parkinson's disease of electrical parameter settings in STN stimulation. Neurology 59:706-713. CrossRef Medline

Okun MS, Vitek JL (2004) Lesion therapy for Parkinson's disease and other movement disorders: update and controversies. Mov Disord 19:375-389. CrossRef Medline

Parr-Brownlie LC, Hyland BI (2005) Bradykinesia induced by dopamine D2 receptor blockade is associated with reduced motor cortex activity in the rat. J Neurosci 25:5700-5709. CrossRef Medline
Paxinos G, Watson C (2007) The rat brain in stereotaxic coordinates, Ed 6. San Diego: Academic.

Pereira EA, Nandi D, Jenkinson N, Stein JF, Green AL, Aziz TZ (2011) Pedunculopontine stimulation from primate to patient. J Neural Transm 118:1453-1460. CrossRef Medline

Rosin B, Slovik M, Mitelman R, Rivlin-Etzion M, Haber SN, Israel Z, Vaadia E, Bergman H (2011) Closed-loop deep brain stimulation is superior in ameliorating parkinsonism. Neuron 72:370-384. CrossRef Medline

Sacrey LA, Alaverdashvili M, Whishaw IQ (2009) Similar hand shaping in reaching-for-food (skilled reaching) in rats and humans provides evidence of homology in release, collection, and manipulation movements. Behav Brain Res 204:153-161. CrossRef Medline

Udupa K, Chen R (2013) Motor cortical plasticity in Parkinson's disease. Front Neurol 4:128. CrossRef Medline

Whishaw IQ, Pellis SM, Gorny BP (1992) Skilled reaching in rats and humans: evidence for parallel development or homology. Behav Brain Res 47:59-70. CrossRef Medline

Yamada N, Kakuda W, Kondo T, Shimizu M, Sageshima M, Mitani S, Abo M (2014) Continuous theta-burst stimulation combined with occupational therapy for upper limb hemiparesis after stroke: a preliminary study. Acta Neurol Belg 114:279-284. CrossRef Medline

Yizhar O, Fenno LE, Davidson TJ, Mogri M, Deisseroth K (2011) Optogenetics in neural systems. Neuron 71:9-34. CrossRef Medline

Zhang F, Wang LP, Boyden ES, Deisseroth K (2006) Channelrhodopsin-2 and optical control of excitable cells. Nat Methods 3:785-792. CrossRef Medline

Zhao S, Ting JT, Atallah HE, Qiu L, Tan J, Gloss B, Augustine GJ, Deisseroth K, Luo M, Graybiel AM, Feng G (2011) Cell type-specific channelrhodopsin-2 transgenic mice for optogenetic dissection of neural circuitry function. Nat Methods 8:745-752. CrossRef Medline 